\title{
PROFILE, BACTERIOLOGY AND ANTIBIOTIC SUSCEPTIBILITY PATTERN OF DIABETIC FOOT ULCERS AT FEDERAL MEDICAL CENTRE, MAKURDI
}

Ojobi $\mathrm{JE}^{\mathrm{I}^{*}}$, Ogiator $\mathrm{MO}^{2}$, Anyim $\mathrm{OB}^{3}$, Abonyi $\mathrm{M}^{4}$

Department Medicine, Federal Medical Centre, Makurdi, Benue state ${ }^{1}$, Benue State University Teaching Hospital, Makurdi ${ }^{2}$, Emeka Odumegwu Ojukwu Teaching Hospital, Awka, Anambra State ${ }^{3}$ and Enugu State University Teaching Hospital, Enugu State. ${ }^{4}$

*Corresponding Author: Dr. Ojobi J. Echobu. Medicine Department, Federal Medical Centre, PMB 1020204, Makurdi, Benue state, Nigeria.E-mail:ojobijoe@yahoo.com.

Received date: March $05^{\text {th }} 2018$, Accepted date: March $26^{\text {th }}, 2018$. Published date: April $20^{\text {th }}, 2018$

\begin{abstract}
The reported increase in the prevalence of diabetes mellitus is expected to be accompanied by a corresponding increase in associated complications. Foot problems are important public health complications of diabetes mellitus. A major obstacle in the management of foot ulcers in diabetes is the colonisation of wounds by virulent pathogens, increasing morbidity and mortality. This was a review of the profile, bacteriology and antibiotic susceptibility pattern of foot ulcers in type 2 diabetes mellitus to aid planning of services and provides a sensible approach to empirical antibiotic therapy while awaiting culture and sensitivity report. It was a hospital based retrospective study in individuals with type 2 diabetes mellitus admitted for foot ulcer(s) over a 3 year period $(2012$ - 2014) at the Federal Medical Centre. Approval for the study was obtained from the Ethics Committee of the institution. Relevant data (gender, age, residence, occupation, diabetes mellitus duration, ulcer duration, glycoslated haemoglobin status) were extracted from the files. One hundred and nine

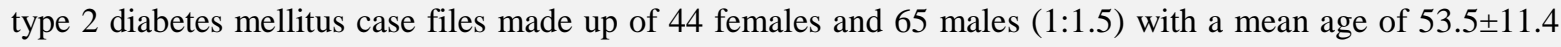
years were extracted. They were mostly farmers in their fifties with poor glycaemic control who had type 2 diabetes mellitus for more than a decade and foot ulcers for more than 6 months. Late presentation, poor glycaemic control, high rate of wound infection with Staphylococcus aureus, resistance to Penicillins and sensitivity to Quinolones were noted.
\end{abstract}

Keywords: Diabetes Mellitus, Ulcer, Bacteriology, Antibiotic Susceptibility

\section{Introduction}

Reliable estimates projected an astronomic increase in the prevalence of diabetes mellitus ${ }^{1}$. The rise in prevalence will be associated with a corresponding increment in associated complications. Foot problems are increasingly important complications of Diabetes Mellitus (DM). These range from mild discomfort through debilitating paraesthesia to fungating ulcers. They are known to be leading cause of admission to hospitals and prolong stay on admission; straining man-power, draining resources and often associated with unnecessary and untimely death., ${ }^{2,3}$ Diabetes associated foot conditions constitute different percentages of diabetes admissions from different reports even in the same country. ${ }^{2,3,5}$ A major obstacle in the management of diabetes related foot ulcer is the colonisation of wounds by virulent bacterial pathogens ${ }^{5}$, increasing cost, morbidity and mortality. 
In this paper, we present a review of the profile, bacteriology and antibiotic susceptibility pattern of foot ulcers in type 2DM patients (T2DM) hospitalized at Federal Medical Centre (FMC), Makurdi. This will engender better understanding of these patients that present with bacteriological and antimicrobial susceptibility patterns of foot ulcer. It will also provide a sensible approach to empirical antibiotic therapy while awaiting results of wound swab microscopy, culture and sensitivity.

\section{Materials and Methods}

Folders of individuals with T2DM admitted at FMC, Makurdi from January 2012 to December 2014 were assessed to determine the profile, bacteriology and antibiotic susceptibility of their foot ulcer(s). Federal Medical Centre is a 400-bed tertiary referral centre in Makurdi, Benue state, Nigeria. Benue state is located in the North-Central region of Nigeria on geographical co-ordinates of latitude $7^{0} 42^{\prime}$ and $10^{\circ} 0^{\prime}$ East, longitude $6^{0} 25^{\prime}$ and $6^{0} 8^{\prime}$ North. Approval for the study was obtained from the Ethics Committee of the institution. Relevant data (gender, age, residence, occupation, duration of diabetes, ulcer duration, glycaemic control at presentation using $\mathrm{HbA1c}$, comorbid conditions) were extracted from the case files. Individuals with other types of diabetes were excluded (e.g. type 1 DM, Latent Autoimmune diabetes in Adults, drugs and endocrinopathies acting as the cause of diabetes). All foot ulcers were swabbed using sterile swab sticks and taken to the laboratory within one hour of sample collection. All swabs were subjected to Gram staining, microscopic examination and culture. Blood, MacConkey and chocolate agar were used as primary isolation media for gram-positive and negative bacteria. The wound specimens were inoculated on these media and incubated appropriately at $35-37^{\circ} \mathrm{C}$. All isolates were subjected to antibiotic sensitivity testing using the disc diffusion technique. The data generated was subjected to simple descriptive statistical analysis using frequencies and percentages.

\section{Results}

A total of 604 T2DM individuals were admitted within the 3 years reviewed with 127 (21\%) of them having foot ulcer(s). Eighteen (14.2\%) had incomplete records (and were subsequently not included in the analysis), while a hundred and nine $(85.8 \%)$ had complete results. There were 44 females and 65 males (1:1.5) with a mean age of $53.5 \pm 11.4$ years. Other aspects of socio-demographic data were as depicted in table I. Relevant clinical data in table 2 shows that majority had DM for more than a decade, had foot ulcer for more than 6 months and also had poor glycaemic control on presentation. The age group $50-59$ had the highest number of patients on admission as depicted in Table 3 while Table 4 showed the observed microbes and their relative frequencies. Repeated swabs from three ulcers did not grow any organism on bacterial culture. One of these swabs eventually became positive for fungi, two remained negative on standard preparation for organisms with very strict handling and for non bacterial pathogens. Figure.I is a graphical presentation of antibiotic sensitivity and resistance pattern showing a high sensitivity to Quinolones and high resistance to Penicillins. 
Table I: Socio-demographic characteristics of participants.

\begin{tabular}{|c|c|c|}
\hline Parameter & Frequency & Percentage \\
\hline \multicolumn{3}{|l|}{ Age } \\
\hline Mean & $53.5 \pm 11.4$ years & \\
\hline Range & $38-92$ years & \\
\hline Distribution: $30-39$ & 3 & 2.8 \\
\hline $40-49$ & 17 & 15.6 \\
\hline $50-59$ & 38 & 34.8 \\
\hline $60-69$ & 28 & 25.7 \\
\hline $70-79$ & 15 & 13.8 \\
\hline $80-89$ & 7 & 6.4 \\
\hline$\geq 90$ & 1 & 0.9 \\
\hline Total & 109 & 100 \\
\hline \multicolumn{3}{|l|}{ Residence } \\
\hline Rural & 49 & 44.9 \\
\hline Urban & 60 & 55.1 \\
\hline Total & 109 & 100 \\
\hline \multicolumn{3}{|l|}{ Educational Level } \\
\hline Primary & 65 & 59.7 \\
\hline Secondary & 30 & 27.5 \\
\hline Tertiary & 14 & 12.8 \\
\hline Total & 109 & 100 \\
\hline \multicolumn{3}{|l|}{ Occupation } \\
\hline Farmers & 58 & 53.2 \\
\hline Civil / public service & 34 & 31.2 \\
\hline Self employed & 5 & 4.6 \\
\hline Unemployed (including retired) & 12 & 11.0 \\
\hline Total & 109 & 100 \\
\hline
\end{tabular}

Table 2: Clinical characteristics of participants

\begin{tabular}{rlll}
\hline Parameter & Frequency & Percentage \\
\hline DM duration & & \\
$-\quad<5$ years & 24 & 22.0 \\
$-\quad 5-10$ years & 33 & 30.3 \\
$-\quad \geq 11$ years & 52 & 47.7 \\
$-\quad$ Total & $\mathbf{1 0 9}$ & $\mathbf{1 0 0}$
\end{tabular}

Ulcer duration

$\begin{array}{llll}- & <3 \text { months } & 30 & 27.5 \\ - & 3-6 \text { months } & 31 & 28.4 \\ -\quad>6 \text { months } & 48 & 44.1 \\ -\quad \text { Total } & \mathbf{1 0 9} & \mathbf{1 0 0}\end{array}$

HbA1c at presentation

$\begin{array}{llll}- & \operatorname{good}(<6.5) & 24 & 22.0 \\ - & \text { poor }(6.5-8) & 35 & 32.1 \\ - & \text { very poor }(>8) & 50 & 45.9 \\ - & \text { Total } & \mathbf{1 0 9} & \mathbf{1 0 0}\end{array}$


Table 3: Admission pattern in each age range

\begin{tabular}{|c|c|c|c|c|c|c|c|c|}
\hline $\begin{array}{l}\text { Age range/ } \\
\text { Year }\end{array}$ & $30-39$ & $40-49$ & $50-59$ & $60-69$ & $70-79$ & $80-89$ & $\geq 90$ & Total \\
\hline 2012 & 1 & 4 & 12 & 11 & 3 & 2 & 0 & 33 \\
\hline 2013 & 0 & 7 & 16 & 10 & 9 & 3 & 1 & 46 \\
\hline 2014 & 2 & 6 & 10 & 7 & 3 & 2 & 0 & 30 \\
\hline Total & 3 & 17 & 38 & 28 & 15 & 7 & 1 & 109 \\
\hline
\end{tabular}

Table 4: Implicated microorganisms and their relative frequencies

\begin{tabular}{lll} 
Organism & Frequency & percentage \\
\hline Staphylococcus aureus & 34 & 31.2 \\
Escherichia coli & 28 & 25.7 \\
Pseudomonas & 20 & 18.4 \\
Streptococcus & 12 & 11.0 \\
Kliebsiella & 8 & 7.3 \\
Candida albican & 1 & 0.9 \\
Staphylococci + Coliforms & 4 & 3.7 \\
No growth & 2 & 1.8 \\
Total & $\mathbf{1 0 9}$ & $\mathbf{1 0 0}$ \\
\hline
\end{tabular}

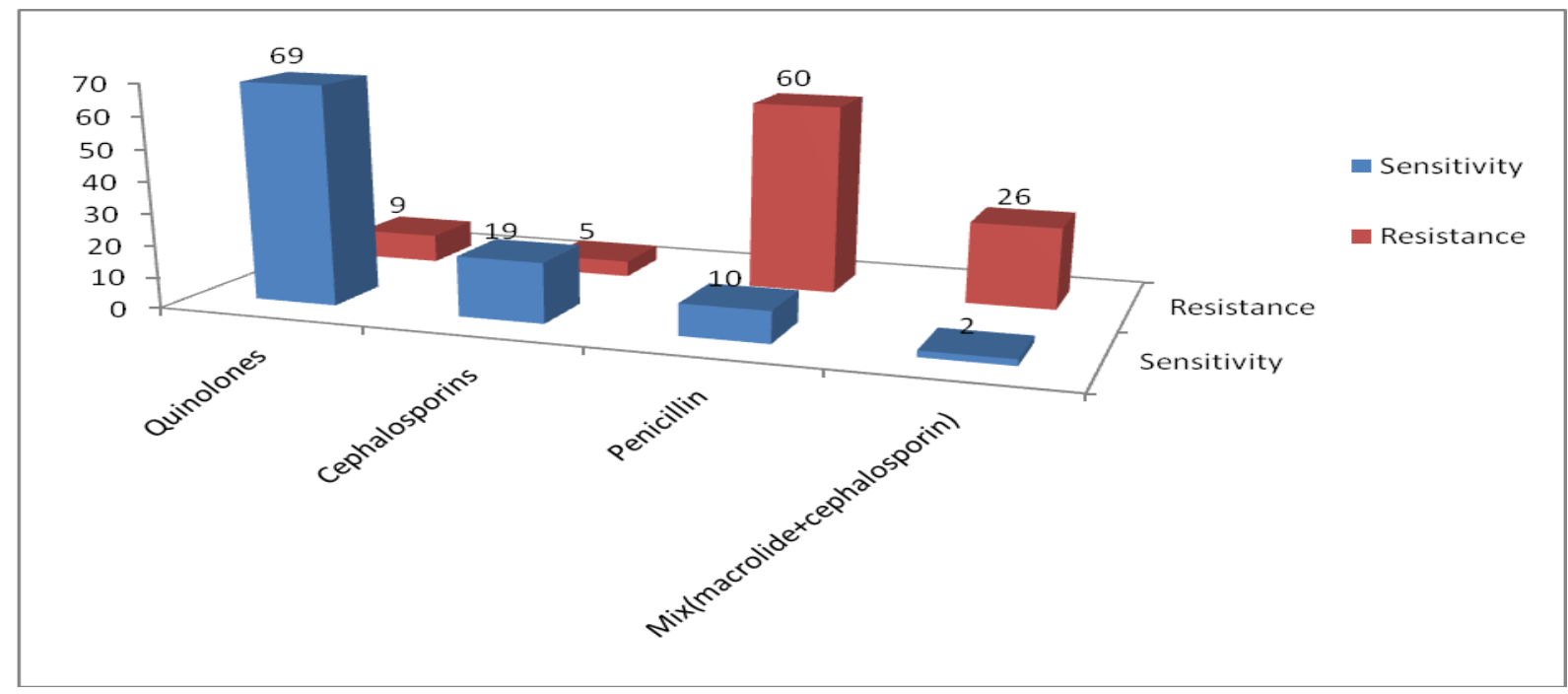

Figure I: Antibiotic Sensitivity and Resistance Pattern 


\section{Discussion}

In this study, most patients with T2DM presenting with leg ulcers were in the prime of their lives as evidenced by a mean age of 53.5 years. The peak age of DM complications are thought to be highest in individuals less than 60 years of age. ${ }^{6,7}$ Majority of the patients $(58 \%)$ were still under this age. The relatively young age of people developing limb ulcer(s) may have economic implications in any economy. Also, complications generally ascribed to older age groups are frequently being encountered in younger patients with diabetes, contributing to early mortality. ${ }^{6}$

The number of patients from the urban areas was more than those from rural areas. Type 2 diabetes is closely associated with (rapid) urbanisation, westernization, sedentary lifestyle and obesity. ${ }^{1,6,7}$ These are common descriptive terms applicable to most urban locale with many rural areas threatening to catch up. ${ }^{1,8}$

Both civil and public servants are known to farm extensively in Benue state where this health institution is located. In the peasant agrarian setting that most of these patients were drawn from, poverty, inadequate foot wear, increased risk of physical trauma, infection during farming activities and spontaneous blisters in bare-feet peasants and farmers were quite common. ${ }^{7,8}$ Farmers constitute more than half of those that presented with foot ulcers in this study. In addition, a situation where almost $60 \%$ of participants had primary or no western education, widespread ignorance about appropriate health promotive and preventive activities would be expected. The higher the educational level, the lower the incidence of foot ulcer. ${ }^{8}$ Other researchers had observed an even higher level of poor western literacy rate amongst their respondents. Akanji et al ${ }^{9}$ observed that up to $68 \%$ of their sample in a prospective study were without western education.

A number of research bodies on foot ulcers in people living with diabetes from the developing world feature late presentation to hospital as a common threat. $^{8,10,11}$ Up to $27.5 \%$ of patients in this study sought medical attention after 3 months of home / alternative / unorthodox treatment as a result of many reasons, including ignorance, fear of orthodox medical practices and inadequate transport. ${ }^{11}$ The challenges posed by late presentation to the hospital by individuals living with diabetes that developed foot ulcer is still begging for a solution. ${ }^{10}$ Sadly, many of the reasons were eminently solvable through education of individuals living with DM by their (primary) health care providers. ${ }^{12,13}$

Generally, the patients in this study had poor glycaemic control as evidenced by $\mathrm{HbA} 1 \mathrm{c}>6.5 \%$ which occurred in $78 \%$ of patients in this study. The Diabetes Control and Complications Trial (DCCT) Research Group were able to demonstrate a direct relationship between poor glycaemic control and microvascular complication $^{14}$. Also, the United Kingdom Prospective Diabetes Study (UKPDS) clearly showed that each percentage point reduction in $A_{1 C}$ was associated with a $35 \%$ reduction in microvascular complications (such as neuropathy, a cardinal cause of foot disease in people living with diabetes). ${ }^{15}$ Other researchers also noted varying degrees of poor glycaemic control in their subjects $^{14,15,16,17}$ especially using casual and fasting plasma glucose estimation. Following from this, comparison would become rather difficult because of lack of uniformity: some researchers used HbAIc while others used random blood glucose or fasting plasma glucose assessment due to cost, convenience or unavailability of HbA1c. . $^{14,16,17}$

As a result prolonged exposure of tissue proteins to glycation processes, the duration of diabetes mellitus is thought to be a predisposing factor to diabetic complications in general, especially in poorly controlled patients. ${ }^{14,15}$ This is understandable in view of the variably long latency in the natural history of diabetes mellitus from the time of the initiating injury through clinical detection (as evidenced by the development of hyperglycaemia) up to the development of complications. ${ }^{16}$

Wound infection is a common occurrence in diabetes ulcer. $^{5,18,19}$ This often lead to prolonged hospital admission ${ }^{18,19}$ and increased cost. ${ }^{19}$ On the whole, gram negative bacilli were the predominant organisms observed on Gram stain in this study, making up $50.9 \%$ of all the bacteria. However, the Gram positive cocci, Staphylococcus aureus constitute the majority of individual isolates at $31.2 \%$. This is in agreement with the findings from other publications that demonstrated a preponderance of S. aureus. ${ }^{20,21,22,23}$ Staphylococcus aureus is a common skin commensal, harboured in the anterior nares by nearly half of the global population and 
colonizing the armpits, perineum, and the respiratory tracts of countless others. Coupled with the relatively reduced immune activity of people living with diabetes mellitus, S. Aureus would become more ubiquitous, invasive and virulent. However, this is not a universal finding as studies equally exist, demonstrating the pre-eminence of a variety of other bacteriae. ${ }^{6,19}$

Apart from monomicrobial pattern, other researchers have been able to culture more than one organism from an ulcer. Indeed, Polymicrobial culture is quite common. ${ }^{5,9,18,19,21}$ In this study, a combination of Staphylocci and Coliforms were cultured from only 4 ulcers out of the 109 studied.

Many factors could explain the 'no growth' observed in 3 cultures. While it could be true that the ulcers were indeed sterile, poor swab technique, wrong storage conditions, long "wait" interval (between collection and inoculation in the lab), wrong growth media / conditions, strict aerobes and anaerobes, inappropriate antibiotics use, among other things should be borne in mind as possible factors in interpreting and taking decisions on this observation. It would be better to err on the side of caution, judging from the history, local findings around and on the ulcer and systemic examinations in evaluating this type of occurrence.

One of the "no growth" swab sample which was finally identified as a fungus was further characterised to be Yeast. Undiagnosed and with inappropriate anti-infective drugs, this ulcer may not heal. The time tested teaching emphasizing the need for further efforts in carrying out cultures of samples from refractory ulcers to ensure fungal colonization (especially Yeast) should be borne in mind. ${ }^{18}$

Two important observations stand out on antibiotic susceptibility testing: the high degree of resistance to Penicillins (especially Ampicillin) and the relatively high rate of sensitivity to Quinolones. The cephalosporins were seldom effective and unless suggested from antimicrobial susceptibility testing, these drugs should not be used as initial therapy for diabetic foot infections in our environment. ${ }^{19}$ The resistance to antibiotics of many of these microbesis not surprising because of drug misuse which is widespread in this environment. It is not uncommon to observe antibiotics being marketed in commercial vehicle parks, in the open markets and supermarkets by unlicensed vendors and being hawked in open trays. Some of the strains of bacterial isolates that colonised the refractory diabetic ulcers in this study may have acquired genes for drug resistance through antibiotic misuse. ${ }^{5}$ Quinolones were therefore, recommended as the initial therapy for people living with diabetes in this environment with infected ulcers while awaiting culture results, which should be used to guide further antibiotic therapy.

\section{Conclusion and Recommendation}

There is a high degree of late presentation as well as poor glycaemic control and a high rate of wound infection due to colonisation by opportunistic pathogens especially bacteria. Staphylococcus aureus was the commonest organism isolated from swabs of foot ulcers in this study. Most of the organisms identified from swab cultures were sensitive to quinolones and resistant to penicillins. This is a major challenge in the management of foot ulcers in individuals living with diabetes where culture and sensitivity tests are not available or unreliable as the correct choice of antibiotics should only be made after antibiotic sensitivity testing. We therefore advocate the use of a Quinolone while awaiting sensitivity results.

\section{Limitations}

Bacterial culture result was a very important component of this study. The observed results may have been different if certain factors affecting the patient and or their investigations were different. For instance, where pathogen yield is a major determinant, wound biopsy is superior to wound swab. However, the centre where this study was undertaken lacked punch biopsy capability at the time these patients were documented.

The patients in tertiary hospitals in poor countries often attempt home management ${ }^{8,24}$ or unorthodox involvement ${ }^{8,11,24}$ before they finally seek attention or are referred to primary / secondary centres. . $^{811,24,25}$ Along this delivery chain of presentation to the tertiary centre, it has been observed that antibiotics use (and misuse) is very common in individuals living with DM nursing an ulcer ${ }^{5}$. Since this was a retrospective study, it was difficult to interrogate prior antibiotics use among the study population. It may be important in this context to know the type(s) 
of antibiotics used, the duration and the timing in relation to the onset of ulcer. Documented references to prior antibiotics use were scanty, with patients not knowing the types of drugs used before presentation. This may also affect the types of bacteria cultured while they were being managed in this facility.

Fastidious organisms, strict aerobes and anaerobes and the procedure with which swabs were taken, stored and handled were important determinants of the types of bacterial yield observed.

\section{Conflicts Of Interest}

None declared

\section{Reference}

1. David Cavan, Joao da Rocha Fernandes, Lydia Makaroff, Katherine Ogurtsova, Sara Webber (eds). Executive summary. Diabetes Atlas. Seventh edition. International Diabetes Federation (IDF), 2015. IDF publications, 2015. $12-13$.

2. Okafor CI, Ofoegbu EN. Indications and outcome of admission of diabetic patients into the medical wards in a Nigerian tertiary hospital. Nig Med J. 2011; 52 (2): 86 - 89.

3. Chijioke A, Adamu AN, Makusidi AM. Pattern of hospital admissions among type 2 diabetes mellitus patients in Ilorin. Nig Endoc Pract. 2010; 4 (2): 6 - 10.

4. Unadike BC, Essien I, Akpan NA, Peters EJ, Assien OE. Profile and outcome of diabetic admissions at the University of Uyo Teaching Hospital, Uyo. International journal of medicine and medical sciences. 2013; 5 (6): 286-289.

5. Orji FA, Nwachukwu NC, Udora EC. Bacteriological evaluation of diabetic ulcers in Nigeria. Afr J Diab Med. 2009; 19 -21.

6. Michael Hirst. Foreword. In: Guariguata L, Nolan T, Beagley J, Linnenkamp U, Jacqmain O, eds. Diabetes atlas. $6^{\text {th }}$ ed. Brussels: International Diabetes Federation (IDF) publishers; 2003: 7 11. www.idf.org / diabetesatlas. ISbn: 2-93022985-3. (Accessed November 1, 2016).

7. Ogbera AO, Chinenye S, Onyekwere A, Fasanmade O. Prognostic indices in diabetic mortality. Ethn Dis. 2007; 17: 721-5.
8. Ojobi JE, Ogiator M, Mohammad H, Kortor NJ, Dunga J, Shidali V. Knowledge And Practice Of Foot Care In Type 2 Diabetes Patients Presenting With Foot Ulcer In Makurdi. Benue Biomedical Journal. 2017; 1: 1 - 8.

9. Akanji AO, Adetunji A. The pattern of presentation of foot lesions in Nigerian Diabetic patients. W Afr J Med1990; 1-4.

10. Eke N. (Editorial). Late presentation begs for a solution. Port Harcourt Med J 2007; 1: 75.

11. Ogbera A, Fasanmade O, Ohwovoriole A, "High costs, low awareness and a lack of care-the diabetic foot in Nigeria. Diab Voice. 2006; 51( 3): 30-33.

12. Masson EA, Angle S, Roseman $P$ Soper C, Wilson I, Cotton M, Boulton AJM: Diabetic foot ulcers: do patients know how to protect themselves? Practical Diabetes 1989; 6: 22-23.

13. American Diabetes Association: Preventive care of the foot in people with diabetes (Position Statement). Diab Care 1998; 21: 2178-2179.

14. Diabetes Control and Complications Trial (DCCT) Research Group. The relationship of glycaemic exposure (HbAlc) to the risk of development and progression of retinopathy in the diabetes control and complications trial. N Eng J Med 1993; 329: 977-86.

15. UK Prospective Diabetes Study (UKPDS) Group. Intensive blood glucose control with sulphonylureas or insulin compared with conventional treatment and risk of complications in patients with type 2 diabetes (UKPDS 33). Lancet 1998; 352: 837-53.

16. Ogbera AO. Foot ulceration in Nigerian diabetic patients: a study of risk factors. MERA; Diabetes International 2007: 15 - 17 .

17. Young E, Okafor CI. Outcome of diabetic foot ulcer admissions at the medical wards of University of Nigeria Teaching Hospital Enugu, Nigeria. Int J Diabetes Dev Ctries. 2015; 36 (2): $220-227$.

18. Ikeh EI, PuepetFH, Nwadiaro C. Studies on Diabetic Foot Ulcers in Patients at Jos University Teaching Hospital, Nigeria. Afr J Clin Exp Microbiology 2003; 4(2): 52-61.

19. Edo AE, Eregie A. Bacteriology of diabetic foot ulcers in Benin City, Nigeria. Mera: Diabetes International 2007; $21-23$. 
20. Okunola OO, Akinwusi PO, Kolawole BA, Oluwadiya KS. Diabetic foot ulcer in a Tropical setting: presentation and outcome. Nig Endocr Prac 2012; 6(1):. 10-14.

21. Otu AA, Umoh VA, Essien OE, Enang OE, Okpa HO, Mbu PN. Profile, Bacteriology, and Risk Factors for Foot Ulcers among Diabetics in a Tertiary Hospital in Calabar, Nigeria. Ulcers 2013. Accessed from http://dx.doi.org/10.1155/2013/820468 (accessed December 2016).

22. Dagogo-Jack S. Pattern of diabetic foot ulcer in Port Harcourt, Nigeria. Prac Diab Dig1991; 3: 75-8.
23. McLigey O, Oumah S, Otien O, Saul L. Diabetic ulcers - a clinical and bacteriological study. West Afr J Med 1990; 9: 135-8.

24. Ikpeme IA, Udosen AM, NgimNE, Ikpeme AA, Amah P, BelloS, Oparah S. Footcare practices among Nigerian diabetic patients presenting with foot gangrene. Afr J Diab Med. 2010; 18(2): 15 -17 .

25. Edo EA, Edo GO, Ezeani IU. Risk factors, ulcer grade and management outcome of diabetic foot ulcers in a tropical tertiary care hospital. Niger med J 2013; 54(1): 59 - 63. 